\begin{tabular}{|l|l|l||}
\hline \multicolumn{2}{|c|}{ PublisherInfo } \\
\hline \hline PublisherName & $:$ & BioMed Central \\
\hline \hline PublisherLocation & $:$ & London \\
\hline \hline PublisherImprintName & $:$ & BioMed Central \\
\hline \hline
\end{tabular}

\title{
Post-transcriptional regulation of TNF gene expression in vivo
}

\begin{tabular}{|l|l|l||}
\hline \multicolumn{2}{|c|}{ ArticleInfo } \\
\hline \hline ArticleID & $:$ & 241 \\
\hline \hline ArticleDOI & $:$ & $10.1186 /$ ar-1999-66730 \\
\hline \hline ArticleCitationID & $:$ & 66730 \\
\hline \hline ArticleSequenceNumber & $:$ & 198 \\
\hline \hline ArticleCategory & $:$ & Paper Report \\
\hline \hline ArticleFirstPage & $:$ & 1 \\
\hline \hline ArticleLastPage & $:$ & 3 \\
\hline \hline & & RegistrationDate : 1999-9-13 \\
\hline ArticleHistory & $:$ & OnlineDate \\
\hline \hline ArticleCopyright & $:$ & Current Science Ltd1999-9-13 \\
\hline \hline ArticleGrants & $:$ & \\
\hline \hline ArticleContext & $:$ & 130753311 \\
\hline \hline
\end{tabular}


Andy Clark, Affl

Aff1 Kennedy Institute of Rheumatology, London, UK

\section{Keywords}

Animal model, AU-rich element, stability, TNF, translation

\section{Context}

The 3'-untranslated region (UTR) of tumor necrosis factor (TNF) mRNA contains an adenosineuracil-rich element (ARE), with seven repeats of the pentamer sequence AUUUA. Such sequences are known to participate in the regulation of mRNA stability and translation. On the basis of transfection experiments using reporter gene constructs and immortalised myeloid cell lines, the TNF 3'-UTR appears to participate in post-transcriptional regulation of TNF gene expression. However, the role of the TNF 3'-UTR in the regulation of gene expression has not been directly demonstrated in vivo. To generate a murine cell line bearing a precise deletion of the $69 \mathrm{bp}$ ARE from the TNF 3'-UTR. To examine the physiology of this 'knockout' line, and any effects upon TNF gene expression.

\section{Significant findings}

Because of the severe pathology of TNF ?ARE homozygous animals, several experiments were done against the genetic background of a TNF receptor type I (TNFRI) knockout, or using hemizygous animals (ie TNF ?ARE/TNF-). Deletion of the ARE resulted in a profound disregulation of TNF gene expression which was characterised by the following: increased spontaneous and lipopolysaccharide (LPS)-induced TNF protein production, both in vivo and ex vivo; increased sensitivity to lethal endotoxemia; increased TNF mRNA stability; altered kinetics of LPS-induced TNF mRNA accumulation, with a slower, larger and more sustained increase; loss of sensitivity to SB203580 (an inhibitor of the mitogen activated protein kinase p38 and of TNF mRNA translation); impaired sensitivity to translational inhibition by dexamethasone; ectopic expression of TNF mRNA and protein in lung and synovial fibroblasts. No effects upon transcription or pre-mRNA processing were observed. Disregulated TNF gene expression was accompanied by an inflammatory arthritis and an inflammatory gastrointestinal condition which (respectively) resembled rheumatoid arthritis and Crohn's disease clinically and histologically. Using crossbreeding experiments it was demonstrated that both pathologies were absolutely dependent upon TNFRI (p55). However, in TNFRII-/TNFRII- (p75 knockout) mice the joint pathology was exacerbated, and the gut pathology attenuated. In RAG1-deficient mice, which lack mature $\mathrm{T}$ and $\mathrm{B}$ cells, the joint pathology was unaffected but the gut pathology was attenuated. 


\section{Comments}

This paper elegantly demonstrates the central role of the 3'-UTR in several aspects of TNF gene regulation in vivo. Notably, the deletion of the ARE appears to derepress translation both within and outside the myeloid lineage, and to ablate the regulation of gene expression by the p38 pathway. In view of the pleiotropic effects of dexamethasone, the interpretation of the post-transcriptional effects of this reagent may be less straightforward than suggested here. Rather than making direct measurements of mRNA stability, the authors have extrapolated from steady-state mRNA levels, yet the evidence for impaired on- and off-phase regulation of stability is compelling. This dynamic regulation of gene expression is one of the more interesting aspects of the paper. The pathology of the mouse is equally intriguing; however, it remains to be seen how closely the joint disease models human rheumatoid arthritis. The lack of dependence on the adaptive immune system is particularly thought-provoking, as is the almost complete restriction of disease to joints and gut. Perhaps this points to a critical role for AREmediated negative regulatory, or 'off-phase', mechanisms in prevention of TNF overexpression in these tissues.

\section{Methods}

The ?ARE "knockout" was generated by homologous recombination with a genomic fragment from which a 69 bp ARE had been deleted. Recombinant embryonic stem cells were selected by means of a neomycin resistance cassette, which was flanked by loxP sites, permitting its excision at the fertilised oocyte stage by transient cre expression. The rearrangement was confirmed by Southern blotting. Thioglycollate-elicited peritoneal macrophages, bone-marrow-derived macrophages, lung and synovial fibroblasts were obtained by standard methods. TNF protein was measured by ELISA, and mRNA quantitated by northern blotting or by reverse transcriptase (RT)-PCR. Transcription rates were assessed by nuclear run-on assay, and an RT-PCR method was used to examine TNF mRNA splicing. Sensitivity to lethal endotoxemia was assessed, and pathology was examined both clinically and histologically.

\section{References}

1. Kontoyiannis D, Pasparakis M, Pizarro TT, Cominelli F, Kollias G: Impaired on/off regulation of TNF biosynthesis in mice lacking TNF AU-rich elements: implications for joint and gut-associated immunopathologies. Immunity. 1999, 10: 387-398.

This PDF file was created after publication. 